\title{
Sexualidade do Trabalhador da Construção Civil: Percepções sobre a Exploração Sexual de Crianças e Adolescentes
}

\author{
Sexuality of Construction Workers: Perceptions about Sexual Exploitation \\ of Children and Adolescents
}

\author{
Elder Cerqueira-Santos ${ }^{*}, a$, Diogo Araujo DeSousa ${ }^{b}$, Othon Cardoso de Melo Neto $^{a}$ \\ \& Alexsandro Conceição Rocha ${ }^{a}$ \\ ${ }^{a}$ Universidade Federal de Sergipe, São Cristóvão, Brasil \\ $\&{ }^{b}$ Universidade Federal do Rio Grande do Sul, Porto Alegre, Brasil
}

\begin{abstract}
Resumo
Este estudo objetivou investigar os condicionantes da exploração sexual de crianças e adolescentes (ESCA) sob a percepção de trabalhadores de grandes obras (TGOs) e analisar comparativamente grupos de perpetradores e não-perpetradores. Foram entrevistados 288 TGOs em diferentes regiões brasileiras. Dos entrevistados, $67 \%$ apontaram o envolvimento dos colegas de trabalho com ESCA e $25,4 \%$ relataram o próprio envolvimento. As principais variáveis correlacionadas ao problema foram o envolvimento com prostituição, o uso de drogas e o tempo alojado nas obras. O envolvimento com prostitutas despontou como variável mais importante na predição do envolvimento com ESCA. Intervenções nesta área requerem maior conhecimento acerca dos perpetradores, auxiliando na elaboração de perspectivas de enfrentamento mais eficazes.
\end{abstract}

Palavras-chave: Exploração sexual, crianças, adolescentes, trabalhadores de grandes obras.

\begin{abstract}
This study aimed to understand the reasons for sexual exploitation of children and adolescents from the perception of Brazilian construction workers and compare groups of perpetrators and non-perpetrators. Two hundred eighty-eight construction workers were interviewed in different Brazilian regions. $67 \%$ of respondents indicated the involvement of co-workers with the issue and $25.4 \%$ reported their own involvement with it. Main variables correlated to the issue were the involvement with prostitutes, drug use and time out-of-home. Being involved with prostitutes was pointed as the most important variable explaining the involvement with the issue. Interventions in this area require more knowledge about the perpetrators, which may contribute to the development of more effective strategies of confrontation.

Keywords: Sexual exploitation, children, adolescents, construction workers.
\end{abstract}

O trabalho em grandes obras na construção civil constitui-se uma área bastante diferenciada das outras opções do mercado de trabalho, especialmente quando esta tarefa exige a formação de movimentos migratórios do trabalhador. Estima-se que mais de $90 \%$ dos empregados desta área são homens com até 40 anos de idade e com nível de escolaridade baixo - mais da metade não concluiu o ensino fundamental e cerca de $10 \%$ são analfabetos funcionais (Ministério do Trabalho e Emprego - Relação Anual de Informações Sociais [RAIS], http:/ /www.rais.gov.br). A alta mobilidade no trabalho é outra característica marcante dessa profissão. Períodos de emprego e desemprego, afastamento do lar e da família,

\footnotetext{
* Endereço para correspondência: Centro de Educação de Ciências Humanas, Departamento de Psicologia, Universidade Federal de Sergipe, Av. Marechal Rondon, s/n, Rosa Else, São Cristóvão, SE, Brasil 49000-000. E-mail: eldercerqueira@yahoo.com.br e diogo.a.sousa@gmail.com
}

falta de formação de redes sociais de apoio (comunidades, igrejas etc.) colocam o trabalhador de grandes obras (TGO) em uma situação diferenciada, inclusive fragilizando os vínculos que se formam entre esses trabalhadores e a comunidade onde estão inseridos.

Alguns estudos realizados com esta população no sudeste da Ásia mostram os efeitos da rede social e do afastamento da família na vida sexual dos trabalhadores. Fica claro que a distância de casa aumenta a probabilidade de sexo extra-marital e de envolvimento com a prostituição, enquanto a proximidade dos lares mantém nos trabalhadores um senso de reputação em relação à família e comunidade. Alguns estudos também relacionaram o estilo de trabalho em construções de grandes obras com problemas de saúde como abuso de álcool e outras drogas e comportamentos sexuais de risco. Ambos os estudos identificam os impactos negativos de algumas situações de trabalho na vida pessoal, comunitária e organizacional dos empregados, com efeitos nas empresas 
e comunidades onde as obras se desenvolvem (Paungphen \& Achara, 2001; Thuy \& Kretchmar, 2008)

Levantamentos realizados no Brasil apontam que em muitos casos existe a utilização de crianças e adolescentes nas redes de prostituição que são organizadas para atender a essa clientela. A exploração sexual de crianças e adolescentes (ESCA) tem sido um problema em vários contextos no Brasil (Ribeiro \& Dias, 2009).

Cerqueira-Santos, Morais, Moura e Koller (2008) afirmam que o movimento de enfrentamento da ESCA, embora ainda tenha que avançar, é um processo que está em curso e que pode ser comprovado, por exemplo, a partir do aumento do número de organizações não-governamentais (ONGs) relacionadas ao tema, das campanhas da mídia, da criação do disque-denúncia (Ligue-100), do desenvolvimento de pesquisas e elaboração de documentos, da produção de livros e artigos sobre o tema.

Morais, Cerqueira-Santos, Moura, Vaz e Koller (2007) esclarecem que há muitos elementos em comum entre a situação de abuso sexual e a de exploração sexual, sobretudo a questão do abuso de poder de um adulto sobre uma criança ou adolescente. No entanto, o caráter comercial é fundamental na ocorrência e definição específica da exploração sexual de crianças e adolescentes. Por conta disso, algumas particularidades, por exemplo, são percebidas na descrição do fenômeno e de seus personagens. Nesse sentido, termos como "comércio sexual", "cliente", "demanda" e "oferta" são bastante frequentes e ilustrativos do poder que o critério econômico tem sobre a situação da exploração sexual de crianças e adolescentes.

Ao mesmo tempo, é importante considerar na literatura sobre exploração sexual o pouco destaque dado às investigações com os "perpetradores". Além da perspectiva da "vítima", é também preciso levar em consideração os condicionantes sociais, culturais, econômicos e psicológicos que podem estar envolvidos na formação da "demanda" do comércio sexual.

No Brasil, os estudos de Cerqueira-Santos et al. (2008) e Morais et al. (2007) investigaram esta perspectiva tendo como participantes motoristas de caminhão. Tais estudos mostraram a concepção destes homens sobre o seu próprio envolvimento com a exploração sexual de crianças e adolescentes nas estradas do Brasil e culminaram num projeto de intervenção nacional denominado "Programa Na Mão Certa" (da Childhood Brasil, http:// www.namaocerta.org.br).

Como afirma Santos (2004), trata-se de entender o fenômeno da ESCA a partir da perspectiva do perpetrador e não mais somente da perspectiva da vítima. Morais et al. (2007) argumentam que "tão importante quanto perguntar a uma criança/adolescente ou a outras pessoas o porquê delas se 'prostituírem' é perguntar o porquê de algumas pessoas preferirem fazer sexo e/ou serem clientes do comércio sexual de crianças e adolescentes" (p. 264). Tal concepção exime a responsabilidade das crianças e adolescentes por sua condi- ção e implica na questão, desde o início, os adultos perpetradores que criam e alimentam a demanda por esse tipo de serviço.

A fim de aprofundar a análise acerca do fenômeno da ESCA, faz-se necessário conhecer o comportamento sexual do trabalhador de grandes obras de construção civil e infraestrutura, tidos como potenciais perpetradores da ESCA. Davidson (2001) define o "explorador sexual" como a pessoa que, através de uma relação de desigualdade de poder, entra em contato sexual direto com a criança ou obtém algum lucro pelos serviços sexuais dela. Esse explorador, aqui referido como perpetrador da ESCA, é definido por ter contato sexual direto com a criança e também por ter com ela uma relação de pagamento pelos serviços oferecidos, isto é, pela relação estabelecida, sobretudo, a partir de uma lógica comercial.

A inclusão da perspectiva do perpetrador da exploração sexual de crianças e adolescentes, representados neste estudo pelos trabalhadores de grandes obras, visa a oferecer uma perspectiva mais ampla de compreensão e enfrentamento dessa problemática. Trata-se de compreender os principais motivadores externos, como fatores sociais e condições de trabalho, e condicionantes internos, como motivações pessoais psicossociais, que levam esses homens e profissionais a abusar sexualmente de crianças e adolescentes, estabelecendo com as mesmas uma relação de troca mercantilizada.

Como argumentam Cerqueira-Santos et al. (2008), os homens que se relacionam com crianças em um contexto comercial podem cometer este ato pelas mais variadas razões, desde financeiras até culturais. Por exemplo, eles podem acreditar que o desejo sexual masculino é incontrolável, o que facilitaria a procura por serviços sexuais, sejam eles fornecidos por crianças ou adultos. Além disso, muitos que são clientes da ESCA podem também acreditar que a relação entre eles e as crianças e adolescentes é meramente comercial, e que a criança com a qual se relacionam possui um status menor do que as crianças que não se envolvem com esse tipo de atividade.

O objetivo do presente estudo é compreender os condicionantes da exploração sexual de crianças e adolescentes sob a percepção de trabalhadores de grandes obras brasileiros, a partir de alguns pontos específicos a serem analisados. Busca-se oferecer uma análise comparativa entre os grupos de perpetradores e não-perpetradores da exploração sexual de crianças e adolescentes, identificando possíveis diferenças e semelhanças entre esses dois grupos de TGOs.

\section{Método}

\section{Participantes}

A composição total da amostra consistiu de 288 trabalhadores de grandes obras civis brasileiros (todos do sexo masculino) que estão ou estiveram alojados nas imediações de grandes construções, no período de maio a 
outubro de 2009, em cinco Estados brasileiros: Goiás, Minas Gerais, Santa Catarina, São Paulo e Rondônia.

A composição hierárquica da amostra variou para contemplar diferentes cargos dentro da população de TGOs. Do total entrevistado, 6,4\% englobaram trabalhadores administrativos ou de cargo de supervisão e o percentual restante foi composto de trabalhadores de frente de obra. A escolha por maior número de trabalhadores operacionais se deveu a dois motivos: primeiro, há na população um número significativamente maior de operacionais e, segundo, esta parcela estaria supostamente mais vulnerável a motivadores externos da ESCA.

Setenta e três participantes $(25,4 \%)$ relataram já terem saído uma ou mais vezes com crianças ou adolescentes em relação de comércio sexual, compondo o grupo dos perpetradores, enquanto que os outros $215(74,6 \%)$ responderam nunca tê-lo feito, o grupo dos não-perpetradores.

\section{Instrumento}

Foi utilizado um questionário baseado no instrumento desenvolvido e descrito por Cerqueira-Santos et al. (2008) e Morais et al. (2007). O instrumento contava com 53 questões (entre abertas, de múltipla escolha e escalas), que abordavam os seguintes temas: dados biossociodemográficos; caracterização da profissão; uso de drogas e vida sexual; conhecimento sobre comércio sexual nos arredores dos alojamentos das obras; exploração sexual de crianças e adolescentes (meninos e meninas); e conhecimento sobre a legislação e os órgãos que fazem valer os direitos destes. Para as análises estatísticas deste estudo foram utilizadas apenas questões fechadas de múltipla escolha.

As questões para a entrevista foram formuladas utilizando-se uma terminologia adaptada à linguagem popular, para melhor entendimento dos participantes. Por exemplo, referiu-se à exploração sexual de crianças e adolescentes como "prostituição infantil", o juizado da infância e da adolescência como "juizado de menores", o Ligue-100 como "disque-denúncia" e assim por diante.

Ao final do instrumento, havia uma folha de registros em anexo a ser preenchida pelo entrevistador com suas impressões sobre o participante (confiabilidade, disponibilidade em participar etc.), relatos abertos referentes ao conhecimento e/ou uso de serviços de exploração sexual de crianças e adolescentes, dentre outras informações qualitativas relevantes à pesquisa.

\section{Procedimentos}

O processo de coleta de dados teve como base a metodologia da Inserção Ecológica, descrita e proposta por Cecconello e Koller (2003) para o estudo do desenvolvimento-no-contexto. De acordo com essa perspectiva, os pesquisadores inseriram-se no ambiente de pesquisa (alojamentos de hidrelétricas e gasoduto espalhados pelo Brasil), a fim de estabelecer uma relação de maior proximidade com o seu objeto de estudo e, assim, responder às questões de pesquisa. Os cuidados metodológicos quan- to ao uso da inserção ecológica começaram desde o treinamento e preparação teórica da equipe de pesquisa.

O processo teve início com a imersão no campo de pesquisa a partir de profundo contato com a "cultura dos TGOs", o que incluiu desde o acesso a publicações da área até visitas a canteiros de obras, alojamentos e elaboração de diários de observação. Assim, entende-se que a inserção ecológica aconteceu não somente no momento das entrevistas, mas também no processo de imersão no campo de investigação. Nesse sentido, tão importante quanto os dados das próprias entrevistas realizadas, foram as anotações feitas em diários de campo elaborados pelos pesquisadores acerca dos diversos momentos de interação com as diferentes pessoas no contexto estudado.

Nos alojamentos, a inserção inicial da equipe para a coleta envolveu a apresentação do objetivo geral da pesquisa e dos entrevistadores aos responsáveis pela área de construção (equipe administrativa). Após a apresentação, a equipe de entrevistadores recebia instruções acerca das normas de segurança no local, como a necessidade dos Equipamentos de Proteção Individual (EPI) e, após a autorização, dava início ao trabalho. Os TGOs foram abordados quando estavam conversando com colegas, caminhando sozinhos ou em pequenos grupos, nas áreas de lazer, lanchonetes, lavanderias ou próximos às tendas no alojamento. Evitou-se incomodá-los nos seus horários de refeição, dentro dos seus quartos, quando estavam envolvidos em alguma atividade (lavando roupas, assistindo televisão, jogando sinuca etc.).

$\mathrm{O}$ participante era entrevistado por um membro da equipe de pesquisa, individualmente, que anotava as respostas do entrevistado. As entrevistas duraram, em média, 40 minutos (variando de 30 minutos a 2 horas). Concluída a aplicação do questionário, o entrevistador preenchia a folha de registros em anexo.

\section{Análise de Dados}

Foram realizadas análises estatísticas de cunho descritivo, bivariadas e multivariadas. Para as análises descritivas foram realizados levantamentos de frequência, percentual e médias para as variáveis sociodemográficas e experiências sexuais dos participantes. Análises bivariadas foram realizadas para comparação entre aspectos dos grupos de perpetradores e não-perpetradores, a partir de testes $t$ de Student e Qui-quadrado. Finalmente, foi realizada uma análise de regressão logística entre dados sociodemográficos, questões de trabalho e envolvimento com comércio sexual como modelo preditivo para o envolvimento de trabalhadores de grandes obras como perpetradores da exploração sexual de crianças e adolescentes.

\section{Questões Éticas}

Os aspectos éticos que garantem a integridade dos participantes deste estudo foram assegurados com base na Resolução $n^{\circ} 196$, que consiste em diretrizes e normas 
Cerqueira-Santos, E., DeSousa, D. A., Melo Neto, O. C. \& Rocha, A. C. (2012). Sexualidade do Trabalhador da Construção Civil: Percepções sobre a Exploração Sexual de Crianças e Adolescentes.

que regulam as pesquisas com os seres humanos (Conselho Nacional de Saúde, 1996), e na Resolução n 016 do Conselho Federal de Psicologia (2000). Além da assinatura do termo de consentimento livre e esclarecido, desde o contato inicial com o participante foi garantida a compreensão das características da pesquisa e dos seus direitos como respondente, inclusive o caráter voluntário da participação e o sigilo das informações. O projeto foi aprovado pelo Comitê de Ética em Pesquisa com Seres Humanos da Universidade Federal de Sergipe e tem registro nacional no Conselho Nacional de Ética em Pesquisa - Ministério da Saúde.

\section{Resultados}

Os 288 trabalhadores de grandes obras foram entrevistados nos Estados de Santa Catarina $(n=79 ; 27,5 \%)$, São Paulo $(n=19 ; 6,6 \%)$, Minas Gerais $(n=43 ; 14,9 \%)$, Goiás $(n=60 ; 20,8 \%)$ e Rondônia $(n=87 ; 30,2 \%)$. A característica de mobilidade desta população garantiu a variabilidade das cidades de origem e dos últimos locais onde trabalharam. Foram entrevistados TGOs de todos os Estados brasileiros, exceto Amapá e Mato Grosso do Sul.

Tabela 1

Caracterização Sociodemográfica da Amostra

\begin{tabular}{llc}
\hline \multicolumn{1}{c}{ Itens } & \multicolumn{1}{c}{ Caracterização } & Percentual (\%) \\
\hline Local da Entrevista & Rondônia & 30,2 \\
& Santa Catarina & 27,4 \\
& Goiás & 20,8 \\
& Minas Gerais & 14,9 \\
Estado Civil & São Paulo & 6,6 \\
& Casado / Relacionamento estável & 51,9 \\
Descendência & Solteiro/Separado/Divorciado/Viúvo & 48,1 \\
& Têm Filhos & 66,3 \\
Escolaridade & Têm Netos & 8,4 \\
& Sabe ler, mas não foi a escola & 1,4 \\
& Analfabeto & 1,4 \\
& Fundamental & 58,7 \\
Renda familiar média mensal & Médio & 33,6 \\
& Superior Completo & 4,8 \\
& R\$ 1,00 - 1000,00 & 55,9 \\
& R\$ 1001,00 - 2000,00 & 28,1 \\
& R\$ 2001,00 - 3000,00 & 10,3 \\
\hline
\end{tabular}

\section{Questões de Sexualidade}

Durante o período em que estão alojados, mais da metade dos entrevistados $(55,5 \%)$ relatou ter relações sexuais $(25,2 \%$ relataram fazer sexo uma vez na semana, seguidos de $12,4 \%$ que disseram fazer uma vez no mês). Quando questionados acerca do que fazem quando sen-
Na descrição dos resultados, o termo "prostituição" será utilizado, pois as perguntas feitas aos trabalhadores de grandes obras usaram esta expressão. Optou-se pela utilização desta palavra porque "exploração sexual de crianças e adolescentes" poderia ser pouco familiar para os participantes. Além disso, o termo "exploração" poderia soar de forma negativa para os trabalhadores, ocasionando assim algumas resistências para a participação, bem como a idéia de culpabilização e julgamento. Na maioria dos itens, as sentenças sobre ESCA foram realizadas considerando a possibilidade de envolvimento de "meninos" e "meninas". No entanto, no decorrer das entrevistas foi constatado que todos os relatos pessoais tratavam de experiências sexuais apenas com "meninas".

A média de idade dos participantes foi de 32,78 anos $(D P=10,91)$ variando entre 18 e 64 anos. Do total da amostra, $51,9 \%$ disseram ser casados ou ter um relacionamento estável com uma companheira. A maioria possui baixa escolaridade e a renda média mensal foi de $\mathrm{R} \$ 1.497,13(D P=\mathrm{R} \$ 1.452,59)$. Muitos TGOs mostraram-se satisfeitos com o valor da sua renda mensal, pois acreditavam que em nenhuma outra profissão conseguiriam uma renda equivalente ou superior, dado o baixo nível de escolaridade. A Tabela 1 sintetiza a caracterização sociodemográfica da amostra. 
Envolvimento com Situações de Exploração Sexual de Crianças e Adolescentes

Em uma escala de 1 a 5 , referente à freqüência com que observam e vivenciam a prostituição e a exploração sexual nos arredores das obras e em cidades próximas, verificou-se que os trabalhadores apresentaram médias altas para questões gerais acerca da exploração sexual de crianças e adolescentes que não os envolviam diretamente enquanto indivíduos, isto é, que se referiam a uma terceira pessoa, como em expressões do tipo "outros" ou os "colegas de profissão" (Tabela 2).

Tabela 2

Médias Atribuídas pelos Trabalhadores de Grandes Obras a Questões de Exploração Sexual Comercial

\begin{tabular}{lcc}
\hline & $M$ & $D P$ \\
\hline A prostituição é comum nas obras por onde ando & 4,52 & 0,96 \\
É comum ver meninos e meninas menores de 18 anos se prostituindo & 3,69 & 1,50 \\
Em geral, meus colegas de obra saem com prostitutas & 4,52 & 0,89 \\
Em geral, meus colegas de obra saem com meninos(as) menores & & \\
de 18 anos para fazer programas & 2,79 & 1,54 \\
Eu costumo sair com prostitutas & 2,39 & 1,50 \\
Acho que alguma prostituta com quem saí tinha menos de 18 anos & 1,49 & 0,97 \\
É comum ver colegas se divertindo com menores de idade & 2,86 & 1,42 \\
Eu já me diverti com crianças e adolescentes & 1,49 & 1,02 \\
É comum ver crianças/adolescentes se prostituindo perto das obras & 2,50 & 1,53 \\
\end{tabular}

Se considerarmos o total da amostra $(N=288), 97,2 \%$ afirmaram que há prostituição nas obras por onde andam e $84,5 \%$ disseram que há a presença de meninos e meninas menores de 18 anos em situação de ESCA. Sobre o uso desses serviços, $97,2 \%$ disseram que seus colegas de obra saem com prostitutas e $66,9 \%$ dos entrevistados afirmaram que seus colegas saem com menores de 18 anos.

Ao falar de suas próprias experiências, os números demonstram uma diminuição: $56,7 \%$ dos entrevistados relataram sair com prostitutas e $25,4 \%$ relataram já terem saído uma ou mais vezes numa relação de comércio sexual com crianças e adolescentes. Por fim, 57,3\% dos entrevistados relataram presenciar ou já ter presenciado crianças e adolescentes "se prostituindo" perto das obras.

\section{Principais Motivos Relacionados à Exploração Sexual de Crianças e Adolescentes}

Quando questionados sobre os motivos pelos quais uma criança ou adolescente se "prostituiria", os principais motivos apontados pelos trabalhadores de grandes obras (tanto os que relataram já ter saído quanto os que não saíram) foram: (a) a necessidade financeira $(67,4 \%)$; (b) a exploração por terceiros (37,2\%); (c) a existência do mercado fácil (33\%); e (d) o fato de as adolescentes "gostarem de sexo e terem prazer" (25,3\%). Categorias menos citadas incluíram: a procura por parte de adultos $(23,5 \%)$, a falta de opção no mercado de trabalho (16,5\%), problemas familiares $(10,4 \%)$ e falta de educação $(5,2 \%)$. $\mathrm{Na}$ categoria outros, estão presentes respostas como: más companhias, vício em drogas, desejo de comprar bens de consumo e vontade de adquirir experiência.
Principais Motivos pelos quais Alguns Homens Preferem ou Buscam Fazer Sexo com Crianças ou Adolescentes

Com relação à formação da "demanda" da exploração sexual de crianças e adolescentes, os TGOs foram questionados sobre quais seriam os motivos pelos quais alguns homens preferem fazer sexo com crianças ou adolescentes. A justificativa mais citada foi a de "safadeza, falta de vergonha na cara" $(54,7 \%)$. A busca de excitação e prazer foi a segunda resposta mais citada $(52,3 \%)$, seguida pelas categorias "sentir-se poderoso" $(23,5 \%)$, "reafirmar a virilidade perante si e os outros" $(21,4 \%)$, "reafirmar a masculinidade" (17,5\%) e "aumentar a autoestima" (14\%).

\section{Principais Motivos pelos quais Alguns Trabalhadores} de Grandes Obras Afirmaram Não Ter Saido com Crianças/Adolescentes

Entre os trabalhadores que afirmaram nunca ter saído com menores de idade, o principal motivo alegado foi o fato de saber que é errado ou ser contra tal prática (28,3\%), compatível com a justificativa de "falta de vergonha na cara, safadeza" para a motivação dos homens que se envolvem com menores de idade.

Em contrapartida à motivação de busca de excitação e prazer mencionada para que alguns homens prefiram fazer sexo com menores de idade, a "falta de tesão" ou a "preferência por mulheres mais velhas" foi o segundo argumento mais usado como uma explicação para que alguns trabalhadores de grandes obras nunca tenham saído com crianças ou adolescentes (19,6\%). Ainda devem ser destacadas as respostas que mencionaram o respeito que alguns TGOs disseram ter por essas crianças e adolescentes, muitas vezes comparando-os a suas 
Cerqueira-Santos, E., DeSousa, D. A., Melo Neto, O. C. \& Rocha, A. C. (2012). Sexualidade do Trabalhador da Construção Civil: Percepções sobre a Exploração Sexual de Crianças e Adolescentes.

filhas ou netas, o que despontou como a terceira categoria mais destacada $(14,7 \%)$. Por fim, outros trabalhadores se referiram ao desejo de evitar problemas com a justiça (13\%). Outras razões mencionadas incluíram a falta de oportunidade, a religião, a fidelidade à esposa, a falta de coragem, o fato de não ter idade para essa prática e o medo de doenças.

Análise Comparativa entre Trabalhadores de Grandes Obras Perpetradores e Não-perpetradores da Exploração Sexual de Crianças e Adolescentes

Foram comparadas as respostas dadas nas entrevistas pelos perpetradores e não-perpetradores da exploração sexual envolvendo crianças e adolescentes, a partir de testes $t$ de Student e Qui-quadrado. A Tabela 3 resume as variáveis analisadas. As médias de idade dos grupos de perpetradores e não-perpetradores não se diferenciaram significativamente, bem como a renda média mensal familiar, o tempo na profissão, o tempo de folga que relataram ter durante a semana e a frequência com que disseram praticar sexo com a companheira ou esposa quando estão em casa. As diferenças entre os índices de auto-estima e de qualidade de vida dos perpetradores e não-perpetradores também não demonstraram significância estatística. De maneira similar, embora o grupo de perpetradores tenha apresentado um índice médio de religiosidade levemente menor e um índice médio de machismo levemente maior que os não-perpetradores, essas variáveis também não atingiram diferenças significativas entre os dois grupos. Esses índices foram extraídos das respostas dos participantes às escalas.

Em contrapartida, o tempo que o TGO passa, em média, no alojamento da obra demonstrou ser uma variável com diferença significativa entre os grupos, bem como a frequência com que cada grupo mantinha relações sexuais enquanto estavam alojados e a quantidade de parceiras por ano. $\mathrm{O}$ grupo de perpetradores passa em média menos tempo alojado por obra e relatou uma média de dias que faz sexo na semana bastante maior, assim como uma maior quantidade de parceiras por ano.

O nível de escolaridade, o estado civil, o fato de ter ou não filhos ou filhas, o número de filhos e o esquema de trabalho dos TGOs (vínculo fixo com empresa ou irregular) não demonstraram diferença significativa entre os dois grupos, assim como a imagem que eles acreditam ter perante a sociedade e a religião que professam. Além disso, tanto perpetradores quanto não-perpetradores relataram dificuldades de profissão similares. O uso de métodos para evitar AIDS e outras DSTs, as preferências por categorias específicas de parceiras, as justificativas que eles citaram para a exploração sexual de crianças e adolescentes e o preço relatado do programa com menores de 18 anos também não se diferenciaram significativamente entre os grupos.

Por outro lado, o fato de ter netos, as atividades praticadas pelos TGOs durante seus momentos de folga e o envolvimento com drogas foram variáveis que se diferenciaram significativamente entre perpetradores $\mathrm{e}$ não-perpetradores. As respostas dadas ao que fazem quando sentem desejo sexual e estão alojados, os relatos de envolvimento com prostitutas adultas e o conhecimento que demonstraram ter acerca das instituições e serviços de proteção ao menor também se diferenciaram de maneira significativa entre os grupos. A frequência de perpetradores foi maior entre os que não eram avôs que entre aqueles que já tinham netos. Além disso, os perpetradores afirmaram que faziam sexo e saíam para conhecer a cidade em suas horas de folga com maior frequência que os não-perpetradores, assim como o uso de álcool, de cigarro e de drogas ilícitas foi também apontado com maior frequência entre o grupo de perpetradores. Quando sentem desejo sexual, o grupo de perpetradores relatou que buscam prostitutas e saem com alguém da comunidade com maior frequência que os não-perpetradores, os quais disseram que fazem outra coisa para esquecer e esperar voltar para casa mais frequentemente que os perpetradores. Além disso, de forma geral, houve frequência muito maior de perpetradores $(42,5 \%)$ entre aqueles que afirmaram sair com prostitutas do que entre os que disseram não o fazer $(3,3 \%)$. Por fim, a frequência de perpetradores foi menor entre os que afirmaram conhecer o "disque-denúncia" do que entre os que disseram não conhecer. 
Tabela 3

Comparação entre Perpetradores e Não-Perpetradores da Exploração Sexual de Crianças e Adolescentes

\begin{tabular}{|c|c|c|c|c|}
\hline & & $\begin{array}{r}\text { Perpetrador } \\
\qquad M(D P)\end{array}$ & $\begin{array}{r}\text { Não-perpetrador } \\
\qquad M(D P)\end{array}$ & $t(p) / \chi^{2}(p)$ \\
\hline \multicolumn{2}{|l|}{ Idade } & 30,93 anos $(10,15)$ & 33,39 anos $(11,08)$ & $1,66(0,286)$ \\
\hline \multicolumn{2}{|l|}{ Renda familiar } & $\mathrm{R} \$ 1.172,11(1.616,66)$ & $\mathrm{R} \$ 1.619,07(802,64)$ & $2,234(0,006)$ \\
\hline \multicolumn{2}{|l|}{ Tempo de profissão } & 7,75 anos $(8,63)$ & 8,15 anos $(9,35)$ & $0,317(0,319)$ \\
\hline \multicolumn{2}{|c|}{ Tempo médio por obra (alojamento) } & 7,75 meses $(4,58)$ & 10,61 meses $(9,51)$ & $2,287(<, 001)$ \\
\hline \multicolumn{5}{|c|}{ Frequência de relações sexuais } \\
\hline \multicolumn{2}{|l|}{ quando alojados } & 2,57 dias $(2,08)$ & 1,14 dias $(1,79)$ & $5,522(<, 001)$ \\
\hline \multicolumn{2}{|l|}{$\mathrm{N}^{\mathrm{o}}$ de parceiras/ano } & $17,29(28,61)$ & $5,95(8,49)$ & $4,933(<, 001)$ \\
\hline \multicolumn{2}{|l|}{ Índice de religiosidade } & $16,59(6,64)$ & $18,45(5,70)$ & $2,29(0,228)$ \\
\hline \multicolumn{2}{|l|}{ Índice de machismo } & $21,13(4,91)$ & $19,15(4,17)$ & $2,59(0,108)$ \\
\hline \multirow[t]{4}{*}{ Escolaridade } & Não foi à escola & $25,0 \%$ & $75,0 \%$ & \\
\hline & Fundamental & $29,3 \%$ & $70,7 \%$ & \\
\hline & Médio & $30,6 \%$ & $77,3 \%$ & \\
\hline & Superior & $0 \%$ & $100 \%$ & $6,434(0,092)$ \\
\hline \multirow[t]{2}{*}{ Estado Civil } & Não casado & $30,1 \%$ & $69,9 \%$ & \\
\hline & Casado & $20,5 \%$ & $79,5 \%$ & $3,444 \quad(0,063)$ \\
\hline \multirow[t]{2}{*}{ Ter filhos } & Sim & $25,0 \%$ & $75,0 \%$ & \\
\hline & Não & $25,5 \%$ & $74,5 \%$ & $0,009(0,923)$ \\
\hline \multirow[t]{2}{*}{ Ter netos } & Sim & $8,7 \%$ & $91,3 \%$ & \\
\hline & Não & $26,7 \%$ & $73,3 \%$ & $3,643(0,05)$ \\
\hline \multirow[t]{3}{*}{ Atividades de lazer } & Beber & $54,2 \%$ & $36,5 \%$ & $6,932(0,008)$ \\
\hline & Fazer sexo & $62,5 \%$ & $44,1 \%$ & $7,293(0,007)$ \\
\hline & Conhecer a cidade & $69,4 \%$ & $55,5 \%$ & $4,344(0,037)$ \\
\hline \multirow[t]{3}{*}{ Uso de Drogas } & Bebida & $88,9 \%$ & $66,4 \%$ & $13,551(<, 001)$ \\
\hline & Cigarro & $49,3 \%$ & $35,5 \%$ & $4,222(0,04)$ \\
\hline & Drogas ilícitas & $35,8 \%$ & $24,6 \%$ & $3,184(0,05)$ \\
\hline \multirow{5}{*}{$\begin{array}{l}\text { O que faz quando sente desejo } \\
\text { sexual e está alojado }\end{array}$} & Busca prostituta & $69,4 \%$ & $26,5 \%$ & $42,181(<, 001)$ \\
\hline & Sai com alguém & & & \\
\hline & da comunidade & $33,3 \%$ & $20,9 \%$ & $4,58(0,032)$ \\
\hline & Faz outra coisa & & & \\
\hline & para esquecer & $13,9 \%$ & $39,3 \%$ & $15,756(<, 001)$ \\
\hline \multirow[t]{2}{*}{ Sai com prostitutas } & $\operatorname{Sim}$ & $42,5 \%$ & $57,5 \%$ & \\
\hline & Não & $3,3 \%$ & $96,7 \%$ & $56,472(<, 001)$ \\
\hline \multirow[t]{2}{*}{ Conhece disque-denúncia } & Sim & $20,4 \%$ & $79,6 \%$ & \\
\hline & Não & $34,4 \%$ & $65,6 \%$ & $6,433(0,011)$ \\
\hline
\end{tabular}

A última etapa das análises quantitativas concebeu uma análise de regressão logística, tendo como variável de desfecho o envolvimento como perpetradores da ESCA. Tal análise foi composta por três passos, nos quais foram inseridas as variáveis: (a) dados sociodemográficos (idade, nível de escolaridade, renda fa- miliar, estado civil, ter filhos e ter netos); (b) questões de trabalho (tempo alojado em média por obra) e (c) envolvimento com comércio sexual (se costuma sair ou não com prostitutas). A Tabela 4 apresenta os três modelos obtidos nesta análise. 
Cerqueira-Santos, E., DeSousa, D. A., Melo Neto, O. C. \& Rocha, A. C. (2012). Sexualidade do Trabalhador da Construção Civil: Percepções sobre a Exploração Sexual de Crianças e Adolescentes.

Tabela 4

Análise de Regressão Logística entre Dados Sociodemográficos, Questões de Trabalho e Envolvimento com Comércio Sexual como Modelo Preditivo para o Envolvimento de Trabalhadores de Grandes Obras como Perpetradores da Exploração Sexual de Crianças e Adolescentes

\begin{tabular}{|c|c|c|c|c|c|c|c|c|c|c|c|}
\hline Variável & Referência & Contraste & RO & $\begin{array}{l}\text { Modelo } 1 \\
\text { IC (95\%) }\end{array}$ & $p$ & RO & $\begin{array}{l}\text { Modelo } 2 \\
\text { IC }(95 \%)\end{array}$ & $p$ & RO & $\begin{array}{l}\text { Modelo } 3 \\
\text { IC }(95 \%)\end{array}$ & $p$ \\
\hline Idade & & & 1,02 & $0,99-1,05$ & 0,170 & 1,01 & $0,97-1,04$ & 0,702 & 1,01 & $0,97-1,06$ & 0,502 \\
\hline Escolaridade & & & 1,30 & $1,01-1,67$ & 0,042 & 1,35 & $1,04-1,75$ & 0,023 & 1,26 & $0,95-1,67$ & 0,115 \\
\hline Renda & & & 1,17 & $0,94-1,47$ & 0,162 & 1,11 & $0,88-1,40$ & 0,385 & 1,08 & $0,83-1,39$ & 0,561 \\
\hline Estado civil & Casado & Não-casado & & & & 1,98 & $0,96-4,07$ & 0,064 & 1,69 & $0,73-3,94$ & 0,223 \\
\hline Ter filhos & Sim & Não & & & & 0,56 & $0,24-1,28$ & 0,170 & 0,50 & $0,19-1,28$ & 0,148 \\
\hline Ter netos & Sim & Não & & & & 3,10 & $0,58-16,71$ & 0,187 & 1,48 & $0,23-9,66$ & 0,683 \\
\hline $\begin{array}{l}\text { Tempo alojado } \\
\text { por obra }\end{array}$ & & & & & & 1,06 & $1,00-1,13$ & 0,036 & 1,06 & $0,99-1,13$ & 0,105 \\
\hline $\begin{array}{l}\text { Sair com } \\
\text { prostitutas }\end{array}$ & Não & Sim & & & & & & & 21,15 & $6,21-72,10$ & 0,001 \\
\hline Nagelkerke R2 & & & 0,067 & & & 0,139 & & & 0,386 & & \\
\hline
\end{tabular}

Nota. RO: Razão de odds; IC: Intervalo de confiança

O primeiro modelo, que investigou alguns dados sociodemográficos (idade, nível de escolaridade e renda), mostrou-se fraco, com uma variância explicada de apenas $6,7 \%$. No entanto, revelou o menor nível de escolaridade como preditor do envolvimento com a ESCA.

No modelo 2, foram inseridas outras variáveis sociodemográficas (estado civil, ter filhos e ter netos) e uma variável de questão de trabalho (tempo que passa alojado em média, por obra). Nesse modelo, o menor nível de escolaridade se manteve como preditor, bem como o estado civil - ser solteiro - e passar menos tempo nos alojamentos das obras. A variância explicada pelo segundo modelo foi de $13,9 \%$.

A análise do modelo 3 revelou $38,6 \%$ da variância explicada. O fato de "sair com prostitutas" despontou como o maior preditor da exploração sexual de crianças e adolescentes nos arredores de grandes obras. A inclusão desta variável específica mostrou-se forte o suficiente para eliminar a significância das variáveis apontadas pelos dois modelos anteriores.

\section{Discussão}

Os trabalhos acerca da Exploração Sexual de Crianças e Adolescentes têm demonstrado a dinamicidade de tal fenômeno e o número de atores envolvidos. A compreensão deste problema a partir de diversos pontos de vista é essencial para o entendimento dos agentes motivadores assim como elementos de risco e proteção que envolvem crianças, adolescentes, famílias, perpetradores, comunidades, empresas e organizações locais e nacionais.

Este estudo investigou um grupo de homens até então desconhecido pela literatura científica nacional. Como apontado, poucos estudos já foram realizados com esta população e não há registros no país de investigações que abordem a sexualidade dos trabalhadores de grandes obras ou da construção civil em geral.

De forma geral, as diferenças entre perpetradores e não-perpetradores da exploração sexual não foram tão grandes, sobretudo no que se refere à caracterização sociodemográfica e à caracterização da profissão. Ambos os grupos são compostos por homens com perfis semelhantes, o que pode contribuir para a desconstrução de um estereótipo do perpetrador da ESCA. Durante o estudo, buscou-se não rotular os participantes como abusadores, a fim de não corroborar algum estigma que esta população já possa sofrer. Esta perspectiva está de acordo com Davidson (2001), pois afirma que nem todos os homens que entram em contato sexual pago com crianças e adolescentes são considerados pedófilos por se envolverem nesta atividade.

As questões relacionais e sexuais emergem como tópico constante na vida dos TGOs. O sexo, assim como as drogas e o álcool, passam a se configurar como algumas das poucas opções de lazer e descontração frente à realidade de queixas e trabalho duro. Tratar da exploração sexual de crianças e adolescentes neste contexto é tentar desnaturalizar algo que já está no cotidiano da maioria destes homens, seja como perpetradores ou testemunhas. A realidade da prostituição nos arredores dos ambientes de grandes obras encobre a crueldade de um comércio que está pronto para divertir, alegrar e encobrir vidas sofridas e mal vistas.

A quantidade de dias nos alojamentos apresentou diferença significativa para o grupo de perpetradores e não-perpetradores, mas, contrariando o que era esperado, o grupo de perpetradores passava menos tempo alojado em cada obra do que o grupo não-perpetrador, surpreendendo a hipótese de que os perpetradores seriam aqueles que passariam mais tempo longe de casa, e se 
mostrando como um preditor para a exploração sexual nas análises de regressão. Ao que parece, os perpetradores passam menos tempo nos locais dos alojamentos, desenvolvendo assim vínculos mais frágeis com as comunidades onde se instalam durante o trabalho.

Entretanto, as análises realizadas mostraram que outras variáveis, relacionadas principalmente ao comportamento sexual do próprio TGO, ao uso de drogas e ao conhecimento dos direitos das crianças e dos adolescentes, parecem ser muito mais determinantes. Os dados mostram que, especificamente, o fato de ter o hábito de sair com prostitutas é um dos mais fortes preditores do envolvimento com a ESCA. Tal constatação reafirma a idéia de banalização do sexo e da naturalização do uso dos serviços sexuais como meio de alcance de prazer e diversão num ambiente hostil e com poucas possibilidades de lazer. Destaca-se, ainda, o maior uso de drogas, sejam lícitas, como a bebida e o cigarro, ou ilícitas, como a maconha e a cocaína, entre os perpetradores.

A falta de conhecimentos sobre os direitos das crianças e dos adolescentes merece ser um ponto destacado, não somente para servir como fator diferenciador entre perpetradores e não-perpetradores, mas sim para mostrar o quão desinformada é a maioria dos TGOs, o que facilita aos participantes a tendência em "encurtar" e relativizar as faixas etárias correspondentes à infância e à adolescência para as crianças/adolescentes residentes nas áreas próximas as grandes obras.

Alguns dos entrevistados deram respostas de que, quando sentiam desejo sexual e estavam nas obras, saiam com "alguém da comunidade, sem pagar". Tal resposta é extremamente ampla, pois a noção de pagamento está baseada no dinheiro. Ou seja, outras formas de convencimento para o sexo podem estar implícitas nesta categoria. Em estudo recente com vítimas de exploração sexual (Cerqueira-Santos, Rezende, \& Correa, 2010), destaca-se o fato de que parte das relações de sexo comercial está baseada em trocas, presentes e drogas, o que pode não caracterizar pagamento sob a perspectiva do perpetrador.

Em suma, pode-se ainda verificar que os perpetradores dificilmente colocaram-se na posição de agentes de proteção dos direitos e dignidade das crianças/adolescentes em situação de exploração sexual. Buscaram, ao contrário, justificar seu comportamento através de falsos mitos ("ela parecia uma mulher", "parecia mais velha", "negou a idade", "não era mais virgem"), os quais implicitamente revelam concepções machistas e adultocêntricas da realidade (Morais et al., 2007).

Como esclarecem Morais et al. (2007), não se trata de afirmar que a criança e o adolescente são seres assexuados, que não possuem jogos e brincadeiras eróticas. $\mathrm{O}$ que se deseja é:

demarcar a clara situação de desigualdade na qual o adulto (seja ele o agenciador, seja ele o cliente final) detém o poder de decidir como esta relação deve se estabelecer, impondo às crianças e ao adolescente suas vontades e desejos. (p. 269)

Com relação à formação da "demanda" da exploração sexual de crianças e adolescentes, o principal motivo relatado pelos TGOs para o fato de alguns homens buscarem fazer sexo com crianças ou adolescentes foi "safadeza, falta de vergonha na cara". Essa resposta representa uma visão de que a prática sexual com crianças e adolescentes é algo moralmente incorreto e, portanto, reprovável. No entanto, a resposta seguinte mais citada, "a busca de excitação e prazer", representa uma visão dos trabalhadores de que esse prazer está quase sempre relacionado ao padrão de beleza da juventude, hegemônico na sociedade, mídia e também entre eles. Essa justificativa reflete uma concepção de que a vontade das pessoas que procuram os serviços sexuais de menores de idade é mais importante do que as vontades e necessidades das crianças ou adolescentes envolvidas. Além disso, outras categorias presentes, como "sentir-se poderoso", "reafirmar a virilidade perante si e os outros", "reafirmar a masculinidade" e "aumentar a auto-estima" também são elucidativas de uma concepção de gênero bastante machista desse grupo social, embora não exclusivo dos TGOs. É uma concepção que atribui maior valor e respeito aos homens que são capazes de seduzir e manter relações com um maior número de mulheres e, de preferência, com mulheres mais jovens que eles e que se enquadrem no padrão de beleza socialmente aceitável (Desouza, Baldwin, Koller, \& Narvaz, 2004; Narvaz, 2005).

Concorda-se com Cerqueira-Santos et al. (2008) quando eles afirmam que "não se trata de diminuir a responsabilidade de cada um nesta questão, mas de entender alguns condicionantes desse comportamento, muitas vezes impensado" (p. 452). O fato do perfil de perpetradores e não-perpetradores ser muito semelhante reforça a idéia de que o envolvimento com a ESCA passa também por razões circunstanciais.

Santos (2004) afirma que deve haver uma mudança de pressupostos na forma de encarar o perpetrador da ESCA. Ao invés de insistir em rótulos, como "pervertidos", "abusadores" e "pedófilos", ou de se limitar a compreensão do fenômeno a uma questão de moral individual, é mais proveitoso analisar as realidades econômicas, sociais, culturais e políticas envolvidas tanto na formação da demanda quanto da oferta do comércio sexual. Por isso é tão importante incluir a figura do cliente ou perpetrador nas ações de enfrentamento da ESCA.

Além disso, é válido ainda ressaltar o papel das empresas na responsabilidade dos impactos trazidos pelos seus empreendimentos. Ações neste nível são fundamentais para a manutenção da cadeia produtiva e de negócios. O movimento migratório provocado pela instalação de grandes obras no interior do país é, sem dúvida, fonte de preocupação de todos os setores envolvidos. Espera- 
se que, a partir deste trabalho, seja possível delinear melhor formas de intervenção mais eficazes e planejamentos futuros que visem as crianças e os adolescentes vitimizados pela ganância potencializada pelos empreendimentos econômicos em locais remotos e normalmente não preparados para receber tal "injeção econômica".

É necessário, conforme defende Santos (2004), trabalhar em diversas frentes. Primeiro, qualificar as intervenções em curso nos campos da prevenção, do atendimento educacional e assistencial às crianças e adolescentes sexualmente explorados. Segundo, quebrar o ciclo de impunidade dos agentes envolvidos na ESCA. Por fim, ampliar o conhecimento e a intervenção com os perpetradores da exploração sexual comercial infanto-juvenil na linha preventiva e reeducacional.

\section{Referências}

Cecconello, A. M., \& Koller, S. H. (2003). Inserção ecológica na comunidade: Uma proposta metodológica para o estudo de famílias em situação de risco. Psicologia: Reflexão e Crítica, 16, 515-524.

Cerqueira-Santos, E., Morais, N. A., Moura, A. S., \& Koller, S. (2008). Exploração sexual comercial de crianças e adolescentes: Uma análise comparativa entre caminhoneiros clientes e não-clientes do comércio sexual. Psicologia: Reflexão e Crítica, 21(3), 446-454.

Cerqueira-Santos, E., Resende, N., \& Correa, P. (2010). Vítimas de exploração sexual: Um estudo comparativo entre interior e capital. Contextos Clínicos, 3(2), 3-18.

Conselho Federal de Psicologia. (2000). Resolução para pesquisas com seres humanos. Resolução $n^{\circ}$ 016/2000, de 20 de dezembro de 2000. Brasília, DF: Autor.

Conselho Nacional de Saúde. (1996). Diretrizes e normas regulamentadoras de pesquisas envolvendo seres humanos. Resolução $n^{\circ}$ 196/1996, de 16 de outubro de 1996. Brasília, DF: Autor.

Davidson, J. O. C. (2001). The sex exploiter. Paper presented at the Second World Congress Against Commercial Sexual Exploitation of Children, Yokohama, Japan. Retrieved November 25, 2007, from http://www.ecpat.net/eng/Ecpat inter/projects/monitoring/wc2/yokohama_theme_sex exploiter.pdf

Desouza, E. R., Baldwin, J., Koller, S. H., \& Narvaz, M. G. (2004). A Latin American perspective in the study of gender. In M. Paludi, C. A. Paludi, \& D. C. DeFour (Eds.), Praeger guide to the Psychology of Gender (pp. 45-65). Westport, CT: Praeger.

Morais, N. A., Cerqueira-Santos, E., Moura, A., Vaz, M., \& Koller, S. (2007). Exploração sexual comercial de crianças e adolescentes: Um estudo com caminhoneiros brasileiros. Psicologia: Teoria \& Pesquisa, 23(3), 263-272.

Narvaz, M. G. (2005). Submissão e resistência: Explodindo o discurso patriarcal da dominação feminina. (Dissertação de Mestrado não-publicada). Universidade Federal do Rio Grande do Sul, Porto Alegre, RS.

Paungphen, C., \& Achara, E. (2001). Construction workers and health problems: A case study in Lame Chabang municipal area in Chonburi Province. Journal of Demography, 12, 67-77.
Ribeiro, M. O., \& Dias, A. F. (2009). Prostituição infanto-juvenil: Uma revisão sistemática. Revista da Escola de Enfermagem da USP, 43(2), 465-471.

Santos, B. R. (2004). Contribuições para um balanço das campanhas de combate ao abuso e exploração sexual de crianças e adolescentes no Brasil. In R. M. C. Libório \& S. M. G. Souza (Eds.), A exploração sexual de crianças e adolescentes no Brasil: Reflexões teóricas, relatos de pesquisa e intervenções psicossociais (pp. 99-147). Goiânia, GO: Casa do Psicólogo.

Thuy, B. T. T., \& Kretchmar, J. (2008). Supervisors and accomplices: Extra-marital sex among migrant construction workers in Ha Noi, Viet Nam. Culture, Health \& Sexuality, 10(1), 189-199.
Recebido: 30/08/2010

$1^{a}$ revisão: 18/05/201

$2^{a}$ revisão: 24/05/2011

Aceite final: $1 \% 06 / 201$ 